\title{
UMA AVALIAÇÃO DO PROJETO TÉCNICO SOCIAL NO PMCMVR Avaliando o Trabalho social na Política Habitacional em Viçosa do Ceará
}

\author{
AN EVALUATION OF THE SOCIAL TECHNICAL PROJECT AT \\ PMCMVR \\ Evaluating social work in the Housing Policy in Viçosa do Ceará
}

\author{
A. Tricia Maria Marques do Brasil \\ Ciaud, Mestrado De Políticas Públicas,Universidade Estadual Do Ceará, Brasil \\ tb070973@gmail.com
}

\section{RESUMO}

Qual a contribuição da assistência social em políticas de habitação? Este trabalho trata desta questão em uma avaliação do Projeto de Trabalho Técnico Social (PTTS), no âmbito do Programa Minha Casa Minha Vida Rural. Sabe-se que a questão agrária no Brasil não se resume a um problema de terras; há também uma "invisibilidade" dos trabalhadores rurais afetados por níveis intoleráveis de pobreza e elevada insalubridade habitacional. No atual escopo normativo, todo empreendimento do PMCMV Rural é obrigado a elaborar um PTTS, considerado um componente estratégico para orientar a mobilização, organização e participação dos beneficiários. A pesquisa se estrutura no estudo do caso do Município de Viçosa do Ceará$\mathrm{CE}$, no período de 2015-2018. A metodologia adotada baseia-se no modelo de avaliação em profundidade. Os resultados sinalizam uma grande fragilidade na execução do PTTS, suas ações mostraram-se lentas e descontinuas gerando nos beneficiários insegurança, descrédito, desmotivação em participar ativamente do Programa.

Palavras-chave: Políticas Públicas - Avaliação; PMCMV Rural; Trabalho e Participação Social; Projeto Técnico de Trabalho Social (PTTS).

Linha de Investigação: 1: Cidade e projeto.

Tópico: Habitação e projeto residencial

\section{Abstract:}

What is the contribution of social assistance in housing policies? This article addresses this issue with an evaluation of the Projeto de Trabalho Técnico Social (PTTS), under the Programa Minha Casa Minha Vida Rural (PMCMV Rural). It is known that the Brazil's agrarian issue is not just a land problem. There is also the "invisibility" of rural workers affected by unbearable levels of poverty and high housing insalubrity. In the current normative scope, every instance of PMCMV Rural has to elaborate a PTTS, which is considered to be a strategic component to guide the mobilization, organization and participation of the beneficiaries. The research is a case study of the city of Viçosa do Ceará-CE, from 2015 to 2018 . The methodology adopted is 


\section{XII $\square$ SÃO PAULO15 17 LISBOA $25 \sim 26$ JUN 2020}

based on the depth evaluation model.Theresults showed a big flaw in the PTTS execution, its actions showed themselves to be slow anddiscontinuous creating a sense of insecurity, discredit and lack of motivation for the beneficiaries to actively enroll in theprogram.

Keywords: Public Policies - Evaluation; PMCMV Rural, Social Work and

Participation, Projeto de Trabalho Técnico Social (PTTS).

Research line: 1. City and design

Topic: Housing and residential design

\section{Introdução}

Afinal, a assistência técnica social é imprescindível quando se trata de políticas de habitação de interesse social? Este trabalho irá buscar respostas para estequestionamento através de uma avaliação do papel e alcance do Projeto de Trabalho Técnico Social (PTTS), no que tange o Programa Minha Casa Minha Vida Rural (PMCMV Rural).

Reconhecendo que o déficit habitacional é um problema importante que se estende pelo país não só na sua zona urbana mas também na sua zona rural e ainda destacando o fato de que apesar de existirem diversos estudos, quando se trata do PMCMVR ainda são insuficiente, é que se compreende a importancia e o interesse em se estudar o PMCMVR do municipio de Viçosa do Ceará, especificamente a localidade conhecida por Macajetuba, no período de 2015 a 2018.

A criação do PMCMV Rural teve como propósito possibilitar ao agricultor familiar, trabalhador rural e comunidades tradicionais 0 acesso à moradia digna no campo, em diversas modalidades, construindo/reformando/ampliando ou concluindo um imóvel já existente. No atual escopo normativo, todo empreendimento do PMCMV Rural é obrigado a elaborar um PTTS, considerado um componente estratégico na medida em que justifica e orienta o trabalho de assistência social para a plena consecução dessa política habitacional, através da mobilização, organização e participação dos beneficiários. Pesquisadores que tratam desta questão afirmam que o trabalho técnico social em políticas públicas tem se constituído em um elemento fundamental nos projetos de intervenção pública, especialmente no que diz respeito à tarefa de viabilizar, de forma bem-sucedida, a participação da comunidade na implementação.

Portanto, considerando o arcabouço institucional e teórico acima resumido, o presente artigo tem como objetivo geral avaliar a atuação do Projeto de Trabalho Técnico Social (PTTS) do PMCMVR do Sítio Macajetuba em Viçosa do Ceará-CE, em um recorte temporal que contempla o período de 2015 a 2018. Como objetivos específicos: Realizar um levantamento e observação da legislação referente a política habitacional; Construir um breve histórico da política habitacional no país; Identificar e analisar criticamente a atuação do PMCMV Rural naquele município, analisando com base nas entrevistas os resultados alcançados da pesquisa.

Quanto a metodologia adotada baseia-se no modelo de avaliação em profundidade, utilizando-se a análise qualitativa com suporte de dados quantitativos, observando-se que não se teve a pretensão em contemplar rigorosamente todas as 04 dimensões que fazem parte deste tipo de avaliação, detendo-se em uma análise de conteúdo, preocupando-se em compreender o PTTS, sua execução, analisando numa visão crítica os relatos. A coleta de dados foi realizada por meio de pesquisa bibliográfica e documental, observação de 


\section{SÃO PAULO $15 \sim 17 \cdot$ LISBOA $25 \sim 26$ JUN 2020}

campo, entrevistas, com posterior análise das falas dos atores envolvidos, além de tabulação em planilhas, construção e interpretações de gráficos para os dados quantitativos.

\section{Políticas habitacionais no brasil: uma síntese histórica}

Não diferente das demais áreas importantes para o desenvolvimento do país e bem-estar da população, no Brasil a habitação irá apresentar um cenário problemático, polemizado e discutido, apesar da disponibilidade imobiliária ser muito maior do que o déficit. A Fundação João Pinheiro descreve que há aproximadamente 7.351 milhões de imóveis não ocupados, sendo 7.051 milhões em condições de ocupação (BRASIL, 2009), demonstrando então uma discrepância no funcionamento do mercado para habitação e na atuação do próprio Estado em utilizar prédios públicos fora de uso ou formular maneiras de uso de domicílios disponíveis para moradia popular, em situação de habitabilidade. De tal maneira que, com certeza haveria uma diminuição dos gastos quando confrontados à construção de novas habitações.

\subsection{O Período Desenvolvimentista (1946-1963)}

No Brasil, criada em 01 de maio de 1946 e regida pelo Decreto-lei no 9.218, a Fundação da Casa Popular (FCP), primeiro órgão federal brasileiro na área de moradia, tinha como finalidade centralizar a política de habitação, durante o governo do presidente Eurico Gaspar Dutra (1946-1951). Essa política foi inexpressiva devido a falta de recursos e as regras de financiamento estabelecidas (MCidades, 2004, p. 09). A restrição da maioria da população no que diz respeito aos direitos a moradia adequada levou ao surgimento das favelas.

\subsection{O Período BNH (1964-1985)}

No governo de Castelo Branco (1964-1967), através do Banco Nacional de Habitação - BNH, foi desenvolvida uma política habitacional constituída por um conjunto de características que deixaram registros fundamentais na estrutura institucional, onde se destacaram eventos, como: Elaboração de um sistema de financiamento que propiciou a captação de recursos específicos e subsidiados, o Fundo de Garantia de Tempo de Serviço - FGTS e o Sistema Brasileiro de Poupança e Empréstimo - SBPE, chegando a conseguir um montante expressivo para o investimento habitacional.

No governo de João Figueiredo (1979-1985), surgiram problemas na área da habitação, como a diminuição dos recursos vindo do FGTS e o aumento da inadimplência. No governo Sarney (1985-1990), foram extintas instituições públicas como o BNH (1986) sobrecarregando a CEF - Caixa Econômica Federal, ocasionando remanejamento de atribuições entre as unidades do governo federal e o desrespeito por parte do governo, dos estudos realizados por grupos de trabalhos do próprio Estado (CARVALHO, 1991, p.53). A crise do Sistema Financeiro de Habitação e a extinção do BNH criaram uma separação em relação à política habitacional no país, com a desarticulação progressiva da instância federal, a fragmentação institucional, a perda de capacidade decisória e a redução significativa dos recursos disponibilizados para investimento na área (MCidades, 2004, p.10).

\subsection{O Período Democrático Contemporâneo (1990-2018)}

Após a promulgação da Constituição Federal de 1988, o governo Collor (1990-1992) realizou pouco avanço quanto ao Sistema Financeiro da Habitação, dando pouca importância a moradia popular, destinando o benefício sem nenhum critério específico, (AZEVEDO, 1990, p. 19). 


\section{SÃOPAULO15 17 LISBOA $25 \sim 26$ JUN 2020

Quanto ao governo de Itamar (1992-1995) criou-se os programas Habitar Brasil (para município com mais de 50 mil habitantes) e Morar Município (município de pequeno porte), que funcionavam por fora do Sistema Financeiro da Habitação. Não havendo mudanças no cenário de crise estrutural do SFH. Com o fim do FCVS - Fundo de Compensação de Variação Salarial, criou-se um plano de amortização baseado no comprometimento de renda (em substituição ao antigo Plano de Equivalência Salarial) e definiram-se percentuais máximos de cobranças de taxas e despesas cartoriais.

Quanto ao governo FHC (1995- 2003) debateu-se a questão habitacional de forma integrada à política urbana e à política de saneamento ambiental, por meio da Secretaria de Política Urbana. No campo da habitação popular as propostas eram: Apoiar programas e projetos propulsores de tecnologia simplificada que viabilizasse a construção de moradias de qualidade a baixo custo; Favorecer as associações e cooperativas de produção de habitações e estimular programas de assistência técnica aos órgãos, entidades e organizações comunitárias, comprometidas com soluções locais e integradas de interesse social (AZEVEDO, 1996, p.24). Quanto às linhas de crédito, os Programas de Crédito Direto ao Cidadão, designados de Cred-Mac e Cred-Casa, seria crédito para construção e a aquisição de materiais de construção. Também existiu o Programa de Arrendamento Residencial - PAR, e o Programa Carta de Crédito; o Programa de Financiamento à Produção e ao Crédito Individual. (AZEVEDO, 1996, p.25). Foi nesse cenário onde se intensificou o atendimento privilegiado a camadas de renda média, uma das marcas da política habitacional tradicional no país.

Sendo assim, para se entender a política habitacional no Brasil até esse período, basta observar o percurso do SFH e do BNH, os quais não foram lineares, separando-se em três etapas: (1) De 1964 a 1969 com a implantação e ampliação do BNH e das COHABs; (2) De 1970 a 1974, havendo um esvaziamento e uma crise do SFH devido a perda do dinamismo das COHABs, quanto a sua fragilidade econômica e a inadimplência dos mutuários; (3) De 1975 a 1980, reestruturação das COHABs, ampliando as construções de moradia para classe média.

Foi nos governos de Lula (2003-2011) que surgiu o Ministério das Cidades (2003), objetivando mudar o cenário na questão habitacional, se organizando com 04 secretarias nacionais, eram elas: Habitação, Saneamento, Mobilidade Urbana e Programas Urbanos, todas no sentido de interligar as políticas setoriais. Fundou o Sistema Nacional de Habitação de Interesse Social, onde só teria direito aos recursos, os estados e município que formasse o chamado CPF, ou seja, com Conselho, Plano de habitação e Fundo. Também foi apresentado o Programa de Aceleração do Crescimento - PAC (2007), visando executar grandes obras de infraestrutura, incluindo entre seus componentes um programa de caráter social e a urbanização de assentamentos precários. E surgiu o PMCMV/PMCMVR.

Quanto ao governo interino de Michel Temer (2017-2018), entre os retrocessos, destaca-se a suspensão do Minha Casa Minha Vida, principal programa habitacional do país, para as faixas de renda mais baixa, a redução de orçamento para desenvolvimento urbano, a desaceleração do crédito habitacional. Ele também não aprovou o Conselho das Cidades e suas instâncias de participação. O diálogo entre Ministério das Cidades e sociedade civil foi reduzido.

Atualmente o que se constata e uma redução dos investimentos e uma tendência que o déficit habitacional aumente. 


\section{XII $\square$ SÃOPAULO15 17 LISBOA $25 \sim 26$ JUN 2020}

\section{O programa minha casa minha vida}

O PMCMV foi lançado, em 2009, com o intuito de combater o problema do déficit habitacional. Sabe-se que este problema acontece em todo o Brasil, pois inúmeras famílias não têm onde morar ou moram em habitações precárias, faltando uma infraestrutura adequada, em locais distantes, ou seja, periferias. Desde então, com 10 anos de existência, o PMCMV já ajudou milhares de pessoas a adquirirem imóvel próprio, realizando um importante incentivo a economia sobretudo no setor da construção civil.

Pensando sobre habitação de interesse social, o período que se desenrola de 1988 - época que começa a vigorar a Constituição Federal/88 - até 2003, quando se forma o Ministério das Cidades, sente-se um vazio deixado pelo extinto Banco Nacional de Habitação - BNH (extinto através do Decreto-Lei no 2.291, de 21 de novembro de 1986) e pela carência de uma estrutura de âmbito federal organizada para a gerencia das políticas urbana e habitacional, numa fragmentação institucional, ineficiência de capacidade decisória e diminuição expressiva dos recursos para o investimento na área.

O cenário da política habitacional vai passar por mudanças com a institucionalização desta política no governo Lula. Este período segue à criação do Ministério das Cidades, definido pelo recomeço do planejamento estatal no setor habitacional, urbano e pela ampliação de recursos e subsídios para a habitação de interesse social (DENALDI, 2012; BUONFIGLIO, 2011). Em 2004 aprova-se a Política Nacional de Habitação (PNH) e o Sistema Nacional de Habitação (SNH) e, em 2005, o Sistema Nacional de Habitação de Interesse Social (SNHIS) e o Fundo Nacional de Habitação de Interesse Social (FNHIS), com o objetivo de garantir que os recursos públicos fossem destinados exclusivamente a subsidiar a população de mais baixa renda (Brasil, 2005).

Portanto, no final do governo FHC (1995-2002) e no primeiro governo de Luís Inácio Lula da Silva (20032006), foi se construindo uma conjuntura adepta à participação do setor privado na promoção habitacional. O equilíbrio macroeconômico do país no final da década de 1990, com o Plano Real, e com as novas direções na política econômica com o governo Lula, principalmente devido à redução das taxas de juros, mudam a disposição dos investidores e de agentes financeiros no tocante à construção civil e ao mercado imobiliário.

Apesar da crise econômica mundial que começa nos Estados Unidos em 2008, o governo brasileiro toma medidas de expansão de crédito e apoio aos setores que estavam com dificuldades, como o setor imobiliário. No sentido de continuar ampliando o mercado habitacional, e no ano seguinte apresenta-se o Programa Minha Casa Minha Vida - PMCMV (Cardoso e Aragão, 2011). Assim, constituído pela Lei n. 11.977, de 7 de julho de 2009, o PMCMV instituiu, até o momento, o mais importante programa habitacional do governo federal, na construção maciça de moradias focando na melhoria do sistema habitacional para a população de baixa e média renda. O programa é composto por dois subprogramas: o PNHU - Programa Nacional de Habitação Urbana (Art. 4ำ, Lei n. 12.424/2011)' e o PNHR - Programa Nacional de Habitação Rural (Art. 11, Lei n. 12.424/2011).

Embora tenha sido formatado como forma anticíclica fazendo frente à crise econômica, o PMCMV desenvolveu uma política social de grande escala, incentivando a geração de empregos e os investimentos na área da construção civil, respondendo à demanda habitacional de baixa renda que o mercado não supria (ARANTES e FIX, 2009; HIRATA, 2011; KLINTOWITZ, 2011).

O público alvo do Programa Minha Casa Minha Vida é o cidadão que for maior de 18 anos ou que seja emancipado e que não possua casa própria. No entanto, famílias com renda mensal bruta de até $\mathrm{R} \$$ 


\section{SÃO PAULO15 17 LISBOA $25 \sim 26$ JUN 2020

$1.800,00$ e que vivem em área de risco, tem preferência no cadastro e são selecionadas pela prefeitura do município onde vive.

Existem quatro faixas de financiamento do Minha Casa Minha Vida: faixa 1, faixa 1,5, faixa 2 e 3. Cada uma determina o preço do imóvel disponibilizado, conforme a renda do beneficiário. As famílias que fazem parte das duas últimas faixas, e querem requerer o financiamento, não dispõem de um subsídio tão alto. Contudo, não se faz necessário aguardar por sorteio, basta ir a uma agência da Caixa Econômica Federal ou do Banco do Brasil e estar dentro do perfil. Vale destacar que o programa também possui modalidades em área urbana e rural com regras definidas para cada uma.

Em 2010, PMCMV é largamente executado, onde inicialmente havia a intenção de construir 1 milhão de moradias na área urban. A segunda versão do Programa, foi apresentada pela Lei n. 12.424/2011, pensando na construção de 2 milhões de casas até 2014.

Embora existam resultados quantitativos positivos, as pesquisas revelaram parte de uma produção habitacional sem qualidade, assim como, tendo como a localização dos empreendimentos em áreas periféricas das cidades, isso devido a interesses especulativos das construtoras, muitas vezes sem nenhuma infraestrutura ou urbanização, dificultando a vida dos beneficiários, tornando-se um programa as vezes inviável no que tange a questão social.(MARICATO, 2011; ROLNIK e KLINK, 2011; PENALVA Eduarte, 2010; HIRATA, 2009). Vale lembrar que estes mesmos problemas já haviam sido vivenciados em outros programas habitacionais de outros governos.

\subsection{O Programa Minha Casa Minha Vida Rural}

O Programa Nacional de Habitação Rural (PNHR) constitui o PMCMVR e atende às necessidades habitacionais dos trabalhadores rurais e agricultores familiares com renda bruta de até $R \$ 78$ mil/anual para subsidiar a reforma ou a produção de imóveis em área rural. Os recursos vêm do orçamento geral da União ou do FGTS. O público alvo do PNHR são agricultores familiares, assentados, beneficiários do Programa Nacional de Reforma Agrária (PNRA), pescadores artesanais, comunidades quilombolas, povos indígenas, bem como outras comunidades tradicionais. Para participar, as famílias são organizadas em grupos de 4 até 50 famílias, por entidade sem fins lucrativos, como o poder público, cooperativas e sindicatos. O PNHR possui três faixas, que são parecidas com as faixas do Minha Casa Minha vida urbano.

\begin{tabular}{|c|l|l|}
\hline $\begin{array}{c}\text { GRUPOS } \\
\text { RENDA }\end{array}$ & GRUPOS RENDA & \multicolumn{1}{c|}{ CARACTERISTICAS } \\
\hline 1 & $\begin{array}{l}\text { Famílias com renda } \\
\text { até } \mathrm{R} \$ 17 \text { mil/ano }\end{array}$ & $\begin{array}{l}\text { O subsídio é concedido pelo Orçamento Geral da União } \\
\text { (OGU) mediante devolução de contrapartida correspondente } \\
\text { a apenas } 4 \% \text { do valor recebido. O pagamento se inicia após } \\
\text { a entrega da unidade. }\end{array}$ \\
\hline 2 & $\begin{array}{l}\text { Famílias com renda } \\
\text { de } R \$ 17.000,01 \text { até } \\
R \$ 33 \text { mil/ano }\end{array}$ & $\begin{array}{l}\text { Prazo de } 12 \text { meses para construir ou reformar, com uma } \\
\text { taxa nominal de juros de 5\% ao ano e o valor do } \\
\text { financiamento de até } \mathrm{R} \$ 30.000,00 .\end{array}$ \\
\hline 3 & $\begin{array}{l}\text { Famílias com renda } \\
\text { de } \mathrm{R} \$ 33.000,01 \text { até } \\
\mathrm{R} \$ 78 \text { mil/ano }\end{array}$ & $\begin{array}{l}\text { A família pode construir a unidade com prazo de pagamento } \\
\text { das parcelas de } 7 \text { a } 10 \text { anos após o término da obra. }\end{array}$ \\
\hline
\end{tabular}

Tabela: Faixas de Renda Modalidade PMCMV Rural. Fonte: Ministério das Cidades. Elaboração CNM. 2018. 


\section{SÃO PAULO15 17 LISBOA $25 \sim 26$ JUN 2020

A partir do ano de 2014, e nos anos seguintes há uma queda impactante das contratações para construções de habitações, principalmente para Faixa 1 do Programa. Vale destacar que a demanda de contratações na Faixa 1 do programa é uma das principais demandas de prefeituras e também onde está concentrado o déficit habitacional. Em 2017 não houve nenhuma contratação de moradia rural nas regiões norte, sudeste e sul, apenas a região nordeste e centro-oeste, havendo a mais forte queda de $99,8 \%$ nas contratações.

A região Nordeste se destaca como a região que mais contratou e entregou unidades na modalidade rural. $\mathrm{Na}$ segunda posição, está a região Sul, e as regiões Norte e Centro-Oeste apresentaram os menores volumes de contratações. Vale destacar que o déficit habitacional rural no país está concentrado nas regiões Nordeste e Norte do país. (Ministério das Cidades, 2018).

Em suma, o PMCMV/PMCMVR ficou conhecido por facilitar e oferecer planos atrativos para o financiamento de imóveis, já que se adéquam à renda de famílias de classe baixa e média. Além de beneficiar famílias que procuram por uma moradia de qualidade, o Programa incentivou e gerou, significativamente, vagas de emprego na indústria de construção civil, aumentando a renda de milhares de outras famílias.

\subsection{O Projeto do Trabalho Técnico Social (PTTS)}

No PMCMVR, o Trabalho Técnico Social (TTS) é uma peça importante na proposição do desenrolar na política habitacional dirigida para classes menos favorecidas. Com base no Caderno de Orientação do Trabalho Social [COTS], o trabalho social é realizado atraves de eixos onde seriam desenvolvidos por meio de uma mobilização e organização comunitária, com temas diversos, como geração de trabalho e renda, educação sanitária e meio ambiente (Gerência Nacional Gestão Padronização e Normas Técnicas et al, 2013). O investimento nesses eixos seria condição para a execução do programa, cuja continuidade dependeria da autonomia dos beneficiários. Um ponto importante na concepção dos programas é a participação e o comprometimento dos beneficiários nas tomadas de decisão, implantação e manutenção dos empreendimentos.

Historicamente refletindo, o PTTS traz uma constatação sobre a dificuldade da população beneficiária em estar preparada ao chamado para participar em prol de seus direitos, por isso, sentiu-se a necessidade que o TTS estabelecesse formas de controle social e participação por meio de instrumentos que desconstrua o imaginário social de direitos como 'favores'.

Existem pontos críticos do Trabalho Social: um é a forma de efetivar a intersetorialidade, sendo essa entendida como a articulação entre as políticas públicas por meio do desenvolvimento de ações conjuntas destinadas à proteção social, inclusão e enfrentamento das expressões da questão social. $\mathrm{O}$ outro é a necessidade de um "salto de qualidade no sentido de uma maior profissionalização do trabalhador social.

De acordo com o COTS - Caderno de Orientação Técnico Social da CEF - Caixa Economica Federal. (Brasília, Maio. 2013), o profissional que deve realizar o Trabalho Técnico Social se responsabiliza por desenvolver maneiras de emancipação social e política dos beneficiários, possibilitando condições de participação e favorecendo um amadurecimento da noção de cidadania. Entretanto, não se encontrou nos documentos, um conceito claro quanto ao perfil profissional exigido para essas atividades, ou quais seriam as exigências de qualificação específica. A proposta do Trabalho Técnico Social deve-se apoiar em princípios que colaboram para o reconhecimento dos beneficiários enquanto sujeitos coletivos, de direitos e deveres e que estes devem ser respeitados. 


\section{SÃO PAULO15 17 LISBOA $25 \sim 26$ JUN 2020

\section{A política habitacional em Viçosa do Ceará}

Viçosa do Ceará teve em 2012 a elaboração do seu Plano Diretor de Desenvolvimento Urbano (PDDU) e seu Plano Habitacional de Interesse Social (PLHIS), estes instrumentos são fundamentais para o planejamento de ações voltadas para as políticas de habitação. O município teve o Programa Morar Melhor que objetivava distribuir, com base em um cadastro da secretaria municipal de ação social, material de construção, para reforma e ampliação. Também aconteceram construção de conjuntos habitacionais sem qualquer infraestrutura em regime de mutirão. O PMCMVR foi o último implementado, com dois empreendimentos, um em 2013 e outro em 2016.

Os contratos celebrado foi entre beneficiários, CEF e uma Cooperativa de Itapipoca. O primeiro projeto de 2013 contemplou duas comunidades (Juá e Macajetuba) e atendeu 38 famílias, o segundo data de 2016 e atendeu 29 famílias domiciliadas em 08 comunidades, situadas no chamado cinturão verde. A pesquisa se detém na localidade de Macajetuba, zona rural que fica bem próxima da sede e é de fácil acesso, além de ter um número maior de beneficiários.

Localizada a apenas $10 \mathrm{~km}$ da sede do Município, a pequena comunidade rural de Macajetuba totaliza uma população de 1.056 pessoas distribuídas em 251 famílias que se mobilizam em uma associação comunitária. Quanto à religiosidade há presença da igreja Católica. No lazer as opções são: futebol e bares. O tipo de habitação predominante na comunidade é de adobe, havendo ainda casas de taipa e poucas de alvenaria. O sistema de ocupação é em sua maioria própria no formato de posse, seguindo da cessão de uso.

A comunidade é assistida com estrutura de PSF - Programa Saúde da Família para o atendimento médico e odontológico. Existe uma escola municipal de ensino fundamental chamada E.E.F Salustiano da Costa Cardoso. A economia é baseada em agricultura de subsistencia e a criação de pesquenos animais. A renda das famílias é complementada com o programa Bolsa Família, benefícios da previdência social e atividades rurais. A comunidade é coberta $100 \%$ por energia elétrica e quanto a água, há o abastecimento por uma caixa d'água de 60 mil litros que é encanada para todas as casas.

Portanto, percebe-se que Viçosa tem uma atuação muito tímida na política de habitação, havendo uma necessidade de um olhar mais atencioso nesta questão pois, apesar de ser uma cidade de médio porte, ela já apresenta diversos problemas sociais característicos de cidade grande e um deles é o déficit habitacional.

\section{Avaliando o Trabalho Social}

Adotou-se como instrumento de coleta a entrevista semiestruturada, com 32 questões organizadas em $\mathrm{VI}$ blocos, sendo algumas perguntas abertas e outras fechadas. O primeiro bloco tratou da caracterização do perfil do beneficiário. O segundo bloco investigou sobre a composição do domicílio. No terceiro bloco indagou-se sobre a moradia que os beneficiários moravam antes. No quarto bloco as perguntas foram sobre as condições da casa do PMCMVR. O quinto bloco foi sobre o nível de satisfação dos beneficiários com o imóvel recebido. No último bloco tratou-se sobre a execução do PTTS.

As aplicações das entrevistas aconteceram na sua grande maioria nas próprias residências, o que permitiu observar e conhecer as condições de cada imóvel. Duraram aproximadamente 2 horas e a pesquisadora deixou os entrevistados bem a vontade.

Seguiu-se então estes passos: (i) pré-análise, isto é, organização, operacionalização e sistematização das informações. As entrevistas foram gravadas com autorização dos entrevistados e transcritas na íntegra. Este processo permitiu a reprodução exata dos depoimentos; (ii) a exploração ou análise do material tendo feito o 


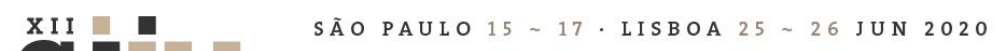

uso de técnicas como a codificação e a categorização, emergindo desta análise quadros de referência; (iii) e o tratamento dos resultados, inferência e interpretação, trazendo a reflexão, embasada nas fontes empíricas, estabelecendo conexões entre a realidade e o aporte teórico.

Sendo assim, foram realizadas entrevistas com 19 beneficiários, com 01 agente de saúde, 01 técnico social da cooperativa, 01 responsável pela cooperativa, 01 assistente de Projetos Sociais da Gerência Executiva de Habitação (GHAB) da CEF de Fortaleza, 01 responsável pela Secretaria da Ação Social do município e da Infraestrutura do município.

Durante as visitas, a pesquisadora foi acompanhada por um agente de saúde que relatou que desconhecia o PTTS e as atividades que deveriam estar acontecendo. $O$ apoio deste agente foi importante pois ele conhecia a dinamica do dia-a-dia dos beneficiários.

A pesquisadora também detinha cópia (desatualizada) do projeto que foi enviado para a Caixa Econômica Federal, e o cronograma do PTTS. Descobriu-se que algumas coisas foram modificadas, antes eram 50 contemplados e descobriu-se que apenas 38 beneficiários haviam sido selecionados, divididos em 27 para a localidade de Macajetuba, ficando o restante para outra localidade, isso foi confirmado pela técnica da cooperativa durante a sua entrevista. Segundo ela, a retirada de alguns beneficiários se deu por não apresentarem a documentação exigida pela CEF. Foi solicitado a cooperativa responsável pela execução da obra e a CEF o acesso ao projeto atualizado, para se verificar as outras possíveis mudanças, mas não foi disponibilizado.

Segundo os entrevistados, não havia uma regularidade na execução das atividades e já faziam mais de 06 meses que a técnica responsavel pela execução do PTTS não aparecia. Essa inconstância desmotivou o interesse dos beneficiários em comparecer nas atividades futuras, levando segundo eles, a uma evasão de cerca de $50 \%$, apesar da técnica social relatar que $85 \%$ dos beneficiários compareciam.

Observou-se também que no cronograma de execução do PTTS, tinha um prazo de 01 ano para a realização das atividades pré-obra, durante a obra e pós-obra. Sendo 06 atividades na primeira fase, 09 na segunda fase e 04 na terceira, totalizando 19 atividades. Os entrevistados relataram terem sido realizadas no máximo 05 atividades e a técnica informou que realizou ao todo 11 ações, faltando segundo ela somente 01 . Há uma constante divergência nas informações.

\section{Participação dos beneficários nas ações do PTS segundo a Técnica da cooperativa}

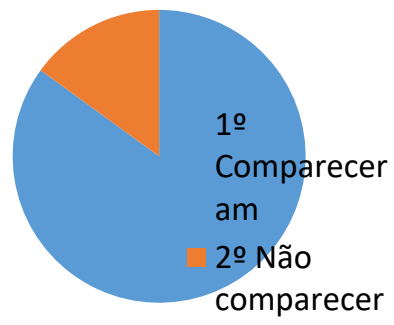

am

Fig. 01: Participação de beneficiários Segundo Fonte: Elaboração própria.2019.

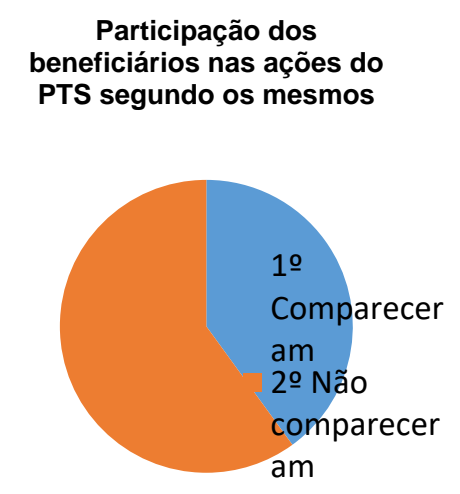

Fig. 02: Participação de beneficiários segundo os mesmos. Fonte: Elaboração própria.2019 


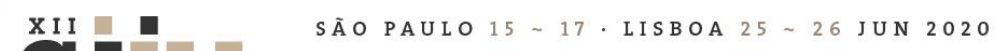

Observou-se que todos os beneficiários, estão com alguma parcela referente ao pagamento para CEF atrasada. São 04 boletos, no valor de $\mathrm{R} \$ 285,00$ reais, onde cada um tem o prazo de 01 ano para pagar e que o prometido foi que receberiam este boleto somente após estarem já morando no imóvel. Porém, sabese que 05 ainda não receberam a casa mas já receberam os boletos para pagamento e a grande maioria foi assim, receberam os boletos antes de recebem a casa.

Apesar de todos os problemas que relataram sobre a casa com relação a infraestrutura, a grande maioria informou que estavam satisfeito com as mesmas, pois informaram que o fato de estarem dentro do que é seu já era uma conquista.

Sobre a execução do PTTS, segundo os entrevistados, 03 beneficiários falaram que não houve nenhum trabalho social. Também dos 19, 07 disseram que houve 02 reuniões. Mais 08 relataram que houve de 03 a 05 atividades. Uma beneficiária disse que houve 10 encontros. Sabendo que eles entendiam por trabalho social, uma pessoa contratada pela cooperativa que vinha realizar reuniões, palestras, oficinas ou visitas domiciliares, todas essas atividades falando sobre o PMCMVR.

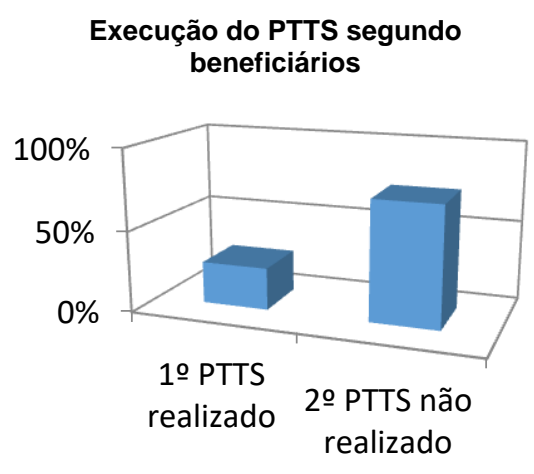

Fig. 03: Execução PTTS segundo beneficiários. Fonte: Elaboração própria.

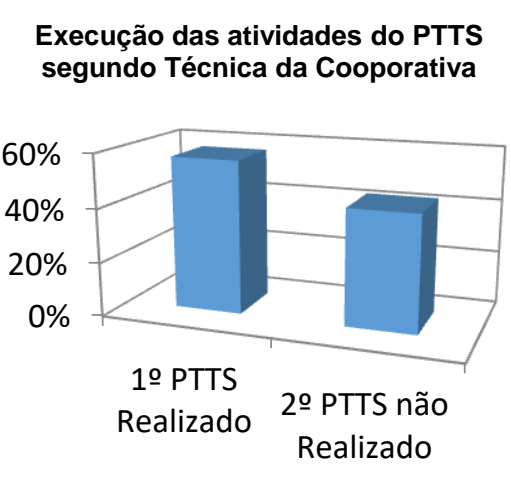

Fig. 04: Execução PTTS segundo TC. Fonte: Elaboração própria.

Todos que participaram de alguma atividade relataram que achavam importante as ações pois ficavam bem informados sobre o programa. Também citaram o material utilizado e o lanche oferecido durante os encontros. Eles estranharam a constant ausencia da técnica, pois segundo eles, ela no primeiro momento informou que seriam muitas atividades e estaria pelo menos 01 vez por mês na localidade para realizar as ações, no entanto, a mesma passava muito tempo sem aparecer, entre um encontro e outro, fazendo com que eles ficassem descrente, desconfiados e desmotivados a participar. Segundo eles, mais da metade faltava os encontros e todos, sem exceção, nunca ouviram falar na palavra PTTS.

Os resultados da pesquisa sinalizam que há uma grande fragilidade no processo de execução do PTTS. Primeiramente, observou-se a ausência de um diagnóstico das características do território e da dinâmica social pré-existente na área de abrangência da intervenção. De acordo com a concepção do PMCMV Rural, esse diagnóstico deveria servir como ponto de partida para o processo de planejamento das intervenções sociais, captando as relações comunitárias, conflitos, limitações e potencialidades nele presentes. A falta deste conhecimento contribuiu decisivamente para gerar nos beneficiários um sentimento de insegurança, descrédito e desmotivação em participar ativamente do Programa. 


\section{SÃO PAULO15 17 LISBOA $25 \sim 26$ JUN 2020

\section{CONCLUSÃO}

A pesquisadora faz uma crítica sobre a falta de fiscalização com relação a realização do PTTS, visto que, no trabalho social não há nenhum acompanhamento in loco, somente o envio de relatórios a CEF, os quais não foi disponibilizado o acesso á pesquisadora. Como esse trabalho é custeado com recurso público, deveria ter um acompanhamento mais de perto e os relatórios deveriam ser de domínio público. O que foi percebido, após as falas da maioria dos beneficiários, é que se poderia ter sido feito um PTTS mais presente e continuo. Ao final, pareceu que o trabalho tornou-se muito frágil, não chegando a alcançar com êxito os objetivos pretendidos pelo projeto, que seria, reforçar o sentimento de pertencimento e apropriação de determinada comunidade, e atuar como ferramenta de transformação social. Lamenta-se, sobretudo, a ausência de uma contribuição fundamental do projeto técnico social nesta comunidade.

\section{BIBLIOGRAFIA}

AZEVEDO, Sérgio. (1996). A Crise da Política Habitacional: dilemas e perspectivas para o final dos anos 90. In: RIBEIRO, Luiz Cesar de Queiroz; AZEVEDO, Sergio de. (Org.). A questão da Moradia nas Grandes Cidades: da Política Habitacional à Reforma Urbana. Rio de Janeiro: Ed. da UFRJ.

BARDIN, L. (2009). Análise de Conteúdo. Trad. Luís A. Reto e Augusto Pinheiro. 5ed. Lisboa: Edições 70.

BONDUKI, N. (2009). Do Projeto Moradia ao Programa Minha Casa Minha Vida. In Teoria e Debate. São Paulo, n. 82, pp. 8-14.

BRASIL. (2009). Ministério das Cidades, Secretaria Nacional de Habitação: Déficit Habitacional no Brasil. Brasília, BH, p.11.

BUONFIGLIO, L. V. e BASTOS, R. D. (2011). O lugar das políticas de habitação popular nas cidades brasileiras. Disponível em: http://xiisimpurb2011.com.br/app/web/arq/trabalhos/4071c402a43c458597efe06f896757f7.pdf. Acesso em: 18 de abril de 2019.

CARDOSO, Adauto L.; ARAGÃO, Thêmis A; JAENISCH, Samuel T (org.) (2017). Vinte e dois anos de política habitacional no Brasil: da euforia à crise. 1. ed. Rio de Janeiro: Letra Capital: Observatório das Metrópoles.

CARVALHO, Sonia Nahas de (1991). A Política Habitacional e a Ação do Estado. Disponível em: <http://www.seade.gov.br/produtos/spp/v05n04/v05n04_09.pdf> Acesso em 11/12/2018.

COTS - Caderno de Orientação Técnico Social. CEF - Caixa Economica Federal. Brasília, Maio..

DENALDI, R. (2012). Política habitacional e urbana: avanços e impasses. Disponível em: http://www.phdu.comuv.com/attachments/article/18/Pol\%C3\%ADtica\%20Habitacional\%20e\%20Urbana\%20a van\%C3\%A7os\%20e\%20impasses\%20\%20-20Rosana\%20Denaldi.pdf. Acesso em 15/04/2019.

HIRATA, F. (2011). Minha casa, minha vida: política habitacional e de geração de emprego ou aprofundamento da segregação urbana? In Revista Aurora, v. 3, n. 4. Disponível em: http://www2.marilia.unesp.br/revistas/index.php/aurora/article/view/1202. Acesso em 10/04/2019. Jornal 0 Estado de S. Paulo-2018.

MARICATO, Ermínia (2011). O impasse da política urbana no Brasil. Petrópolis/RJ, Vozes. 


\section{XII $\mathbf{S}$ ÃO PAULO $15 \sim 17 \cdot$ LISBOA $25 \sim 26$ JUN 2020}

Seminário Internacional de

Seminario Internacional de Investigação em Urbanismo Investigación en Urbanismo

O Programa Nacional de Habitação Urbana - PNHU tem por objetivo promover a produção ou aquisição de novas unidades habitacionais ou a requalificação de imóveis urbanos.

O PNHR tem como finalidade subsidiar a produção ou reforma de imóveis aos agricultores familiares e trabalhadores rurais, por intermédio de operações de repasse de recursos do orçamento geral da União ou de financiamento habitacional com recursos do Fundo de Garantia do Tempo de Serviço - FGTS. Parágrafo único. A assistência técnica pode fazer parte da composição de custos do PNHR. 